\title{
The Relationship between Health Promoting Behaviors and Quality of Life in Nursing Home Residents in Kayseri
}

\author{
Vesile Şenol, ${ }^{1}$ Demet Ünalan, ${ }^{1}$ Ferhan Soyuer, ${ }^{1}$ and Mahmut Argün ${ }^{2}$ \\ ${ }^{1}$ Erciyes University, H.B. Vocational School of Health, 38039 Kayseri, Turkey \\ ${ }^{2}$ Erciyes University, H.B. Vocational School of Health and Department of Orthopaedics and Traumatology, \\ School of Medicine, Kayseri, Turkey
}

Correspondence should be addressed to Vesile Şenol; drvesilesenol@gmail.com

Received 16 July 2013; Revised 2 December 2013; Accepted 3 December 2013; Published 4 February 2014

Academic Editor: Martin J. Sadowski

Copyright (c) 2014 Vesile Şenol et al. This is an open access article distributed under the Creative Commons Attribution License, which permits unrestricted use, distribution, and reproduction in any medium, provided the original work is properly cited.

\begin{abstract}
Background and Aims. Healthy lifestyle behaviors are the major determinant of both prevention health and health related quality of life. The aim of this study was to examine the relationship between health-promoting behaviors and quality of life of elderly individuals living in nursing homes. Methods. The study was performed between October 2008 and 2009, in the city of Kayseri in Turkey, upon 136 individuals, aged 65 and above, living in the Gazioglu Nursing Home. A sociodemographic questionnaire, Standardized Mini Mental Test, Health Promoting Lifestyle Behaviors Profile (HPLP), and WHOQOL-OLD module were used for the gathering of data. Results. The overall HPLP and quality of life (QoL) scores were $118.06 \pm 20.54$ and $43.45 \pm 10.30$, respectively. More than half of the participants have higher points than the mean QoL scores. The HPLP scores of these subjects were significantly higher compared to those with lower points than mean QoL scores. There was a positive relationship between the overall HPLP and WHOQOL-OLD mean scores, except for the autonomy and sensorial function domains. Conclusions. The study result showed that health-promoting behaviors are positively associated with better quality of life scores in the elderly subjects living in a nursing home.
\end{abstract}

\section{Introduction}

As in most other countries, the proportion of the elderly people is increasing every year in Turkey due to decreased birth rates and increased life expectancy. The proportion of those aged 65 years and older in Turkey was approximately $7.3 \%$ in 2011 [1]. In Turkey older adults might feel happier living with their sons and accepting support from their children. Because of the aging society of Turkey and the trend toward more emphasis on the nuclear family than on the extended family, are needed personal support system to an institutionalized, public support system with the aging of the population.

Increased longevity health promotion behaviors become even more important particularly with regard to maintaining function and independence and improving quality of life [2].

Healthy behaviors are the sum of all the behaviors an individual displays or believes in, with the aim of promoting health and preventing disease. A healthy lifestyle is defined as controlling all behaviors that might affect an individual's health and arranging his/her daily activities by choosing appropriate behaviors according to his/her own health state $[3,4]$. In many studies from different countries, it has been established that at least $50 \%$ of deaths per year are related to unhealthy lifestyle behaviors $[5,6]$.

Aging is an expected and accepted physiological process, in which an individual's physical and mental powers are slowly lost, with no return. Apart from individual differences and genetic factors, the aging process is affected to a large extent by lifestyle, occupation, nutrition, chronic diseases, environmental factors, and psychosocial characteristics $[7,8]$.

During this aging process, some physical, psychological, and social changes occur, and this affects the lifestyle, quality of life, and life expectancy of the elderly. Health related quality of life (HRQoL) is a relatively new concept; it focuses upon health status and happiness and is highly sensitive for the measurement of the very important detrimental and destructive effects of chronic diseases upon the geriatric population 
[9]. Healthy lifestyle has been defined as the control by individuals of all factors that might affect their health and choosing behaviors that are appropriate to their own health status while arranging daily activities. Behaviors that enhance health consist of activities that increase the well-being of the individual and enable self-development. A healthy lifestyle includes taking responsibility regarding healthy behaviors, well-balanced nutrition, adequate and regular exercise, not smoking, taking proper hygienic precautions, establishing positive relationships, and stress management $[10,11]$. On the other hand, in elderly people, health-promoting activities should aim to increase functionality, increase life span, and sustain a comfortable, peaceful, pain-free life [11]. In this way, life satisfaction will increase in the elderly, and their perception of the meaning of life will be more positive. Promoting health in the elderly is related to their being independent in their daily activities, having a good cognitive and functional level, and being active. In order to establish the risk factors in the geriatric population and develop target interventions aimed at this group, quality of life evaluations are being used more frequently. General purpose (generic) scales have special importance in evaluating psychological status in the elderly, because most individuals in this age group usually have multiple problems in their lives regarding health and social status [9].

Health promotion increases the healthy life span of individuals, decreases disease burden, slows functional loss, enhances autonomy, and thus increases quality of life. Lima et al. [12] found that quality of life is closely associated with physical activity, smoking, and alcohol consumption. Better HRQoL was seen among the elderly who engaged in physical activity and no smokers and alcohol drinkers one or more times a week. Acree et al. [13] and Laforge et al. [14] showed that there is a positive correlation between physical activity and HRQoL.

The main goal in promoting health is to achieve healthy lifestyle behaviors regarding physical activity, nutrition, and personal hygiene [10]. Drewnowski and Evans [15] reported that biological and medical sciences are united in the belief that optimal nutrition and physical activity make a significant contribution to the overall quality of life for older adults. Although the effect of health-promoting behaviors upon health has been proven, knowledge about the relationship between health-promoting behaviors and quality of life in elderly people is scant and studies are limited. The aim of this study was to examine the relationship between healthpromoting behaviors and quality of life in individuals aged 65 years and above living in nursing homes.

\section{Materials and Methods}

2.1. Design and Sample. This cross-sectional study was conducted in the Gazioglu Nursing Home, located in the city center of Kayseri, a city with 500,000 inhabitants living in the city center and 700,000 in the suburbs between October 2008 and October 2009. The study enrolled a total of 136 nursing home residents aged 65 years and above, who have resided in the nursing home for at least six months or more. Inclusion/exclusion criteria included residents with normal cognitive functions who did not have any documented psychiatric problems, severe visual disturbances, or hearing impairments. 66 subjects were excluded from the study, who have inability to answer the assessment questionnaire due to serious hearing problems or severe communication disorders, cognitive impairment, and being under the age of 65. Monthly per capita household income was determined according to the value of the minimum wages in 2008. The study was approved by the Ethics Committee of Erciyes University. Institutional approval was given by the Provincial Directorate of National Education. Written informed consent was obtained from participants in the study.

\subsection{Measurements}

2.2.1. Mini Mental Status Evaluation (MMSE). The cognitive functions of the subjects were evaluated using the Standardized Mini Mental Status Evaluation (MMSE) test. The Standardized MMSE is "categorized in 5 main topics: (a) orientation, (b) registration memory, (c) attention and calculation, (d) remembering, and (e) language." "The MMSE consists of 11 items with response options that range from 1 (lowest score value) to 6 (highest score value) with an overall total score 30" [16]. The threshold (maybe cut-off point would be better) for the scale is 23 points with scores above the cut-off point representing people who have good mental health. The validity and reliability of MMSE for the Turkish population was established by Gungen et al. [17].

2.2.2. Health Promotion Lifestyle Profile (HPLP). The HPLP scale consists of 48 items and the items are scored on a 4-point Likert-type scale: 1 is never, 2 is sometimes, 3 is often, and 4 is regularly. It has six subscales: (a) self-actualization, (b) health responsibility, (c) exercise, (d) nutrition, (e) interpersonal support, and (f) stress management. The overall score of the scale gives the healthy lifestyle behaviors score. The lowest overall score is 48 points and the highest is 192. High scores from the scale, and from the subscales, are interpreted as positive health-promoting behaviors. The HPLP scale was developed to test the "health-promoting Model" by Walker et al. [28]. The validity and reliability of this scale for our country was established by Esin [18].

2.2.3. World Health Organization Quality of Life Old Module (WHOQOL-OLD). The WHOQOL-OLD consists of 24 Likert-type items that are scored from 1.0 to 5.0. "The six domains are classified as follows: (a) sensorial functions, (b) autonomy, (c) past-present-future activities, (d) social participation, (e) death and dying, and (f) intimacy." The "Sensorial functions" domain investigates the effect of the changes observed in sight, hearing, touch, smell, and taste upon the quality of life; the "autonomy" domain investigates independence, respect, general control of life, independent decision making, and the effect of these factors upon the quality of life; and the "past-present-future activities" domain questions success obtained in the past, and the lifetime satisfaction it brings, and questions the past and feelings and thoughts about the future; the "social participiation" domain examines perceptions about use of time and participation in 
TABLE 1: Distribution of health-promoting lifestyle behaviors profile and WHOQOL-OLD scale mean scores $(n=136)$.

\begin{tabular}{|c|c|c|c|c|}
\hline HPLP subscales & Actual range* & Scale range** & $X \pm \mathrm{SD}^{* * *}$ & Cronbach' $\alpha$ \\
\hline Self-actualization & $13-52$ & $13-52$ & $33.63 \pm 7.52$ & 1.00 \\
\hline Health responsibility & $10-40$ & $10-35$ & $23.18 \pm 4.93$ & 0.60 \\
\hline Exercise & $5-20$ & $5-17$ & $8.36 \pm 3.26$ & 0.27 \\
\hline Nutrition & $6-24$ & $12-23$ & $16.73 \pm 2.38$ & 0.49 \\
\hline Interpersonal support & $7-28$ & $7-28$ & $18.69 \pm 4.61$ & 0.65 \\
\hline Stress management & $7-28$ & $7-25$ & $17.45 \pm 3.79$ & 0.74 \\
\hline Total score & 48-192 & $55-156$ & $118.06 \pm 20.54$ & 0.89 \\
\hline WHOQOL-OLD domains & \multicolumn{2}{|c|}{ Median $(\min -\max )$} & $X \pm \mathrm{SD}$ & Cronbach' $\alpha$ \\
\hline Sensorial functions & \multicolumn{2}{|c|}{$46.87(0.0-100.0)$} & $45.49 \pm 16.41$ & 0.43 \\
\hline Autonomy & \multicolumn{2}{|c|}{$37.50(0.0-93.75)$} & $35.70 \pm 19.96$ & 0.59 \\
\hline Past, present, and future activities & \multicolumn{2}{|c|}{$43.75(0.0-87.50)$} & $44.16 \pm 16.31$ & 0.57 \\
\hline Social participation & \multicolumn{2}{|c|}{$43.75(0.0-93.75)$} & $43.52 \pm 17.10$ & 0.76 \\
\hline Death and dying & \multicolumn{2}{|c|}{$50.00(0.0-93.75)$} & $43.10 \pm 16.21$ & 0.63 \\
\hline Intimacy & \multicolumn{2}{|c|}{$50.00(0.0-100.0)$} & $48.75 \pm 17.96$ & 0.58 \\
\hline Total score & \multicolumn{2}{|c|}{$43.75(6.25-72.92)$} & $43.45 \pm 10.30$ & 0.76 \\
\hline
\end{tabular}

* The lowest and highest values that can be obtained in the original scale.

***The lowest and highest values that are applied to the scale.

*** Mean and standard deviation for each scale.

important activities; the "intimacy" domain examines relations with other people and social assistance; the "death and dying" domain questions subjects, thoughts about the acceptability and inevitability of death, and the meaning of death. WHOQOL-OLD form was developed by Bullinger et al. [19] and the validity and reliability was established for the Turkish population by Eser et al. [9].

2.3. Statistical Analysis. Study data were evaluated using SPSS 18.0 software. Mean standard deviation and percentages were calculated. Independent groups were compared using Student's $t$-test and one-way ANOVA and the power and the direction of the correlation between WHOQOL-OLD total and subdomain scores and HPLP scores were determined using Spearman Correlation Analysis; the factors that affect quality of life were determined using Binary Logistic Regression Analysis. The model included quality of life as the main dependent variable, and self-actualization, health responsibility, exercise, nutrition, interpersonal support, stress management, gender, and marital status as independent variables. $P$ values $<0.05$ were considered as statistically significant. Reliability analyses (Cronbach $\alpha$ coefficient) was calculated for WHOOQL-OLD and HPLP total and subdomain scores. In the determination of the quality of life, the total mean score $(43.45 \pm 10.30)$ was considered as the cut-off point. Then the mean score was transformed to a dichotomous category, which classified subjects as good (had a score above mean score) or poor (had a score under mean score) quality of life.

\section{Results}

The mean age of the residents was $75.05 \pm 6.96$ (minimum 65 and maximum 93) consisting of $59.6 \%$ males, $64.7 \%$ have no formal education and $83.1 \%$ widow/ers and divorced individuals. In $75.0 \%$ of the group, there was at least one chronic disease. Mean monthly income was $248.8 \pm 169.7$ USD ( $\min 40$ and max 692 USD).

The overall and subdomain WHOQOL-OLD and HPLP scores of the study group are given in Table 1 . The mean overall scores were $118.06 \pm 20.54$ for HPLP and $43.45 \pm$ 10.30 for WHOQOL-OLD. Among the mean scores on the HPLP subscales for residents living in nursing home self-actualization had the highest score, followed by health responsibility, interpersonal support, stress management, and nutrition, and exercise is the lowest score. Among the mean scores on the WHOQOL-OLD subdomains intimacy is the highest and autonomy is the lowest score.

Associations between descriptive variables and HPLP and WHOQOL-OLD scale scores was shown in Table 2. The overall HPLP score were significantly higher in male and in married $(P<0.05)$. Overall HPLP score, health responsibility, and interpersonel support subscale scores were significantly higher in married than widow/ers and divorced individuals $(P<0.05)$. No association was found between age, educational level, chronic disease, and overall HPLP score. Total WHOQOL-OLD score has not shown significant association with descriptive variables (Table 2 ).

The overall HPLP and subscale scores were significantly higher in elderly individuals who had higher scores than mean quality of life scores, compared to those who had lower scores. This difference was more prominent in self-actualization subscale score $(P<0.001)$ (Table 3$)$.

There was a moderate positive correlation between the overall WHOQOL-OLD score and overall HPLP score (rho: $0.418, P<0.01$ ) (Table 4). Variables univariate analysis showing a significant relationship with healthy lifestyle behaviors and HPLP subscales in order to assess impact on quality of life together is made of Binary Logistic Regression Analysis Logistic regression yielded a eight variable model, composed of gender, marital status and HPLP subscales, 
TABLE 2: The distribution of health-promoting lifestyle behaviors profile scores according to demographic variables $(n=136)$.

\begin{tabular}{|c|c|c|c|c|}
\hline Variables & $\begin{array}{c}\text { HPLP score } \\
X \pm \mathrm{SD}\end{array}$ & $P$ & $\begin{array}{c}\text { WHOQOL-OLD score } \\
X \pm \mathrm{SD}\end{array}$ & $P$ \\
\hline \multicolumn{5}{|l|}{ Gender } \\
\hline Male & $123.29 \pm 16.21$ & \multirow{2}{*}{$<0.001$} & $43.40 \pm 8.51$ & \multirow{2}{*}{$>0.05$} \\
\hline Female & $110.36 \pm 23.42$ & & $43.54 \pm 12.56$ & \\
\hline \multicolumn{5}{|l|}{ Age group (year) } \\
\hline $65-74$ & $119.78 \pm 20.16$ & \multirow{3}{*}{$>0.05$} & $43.68 \pm 9.47$ & \multirow{3}{*}{$>0.05$} \\
\hline $75-84$ & $117.14 \pm 20.06$ & & $43.65 \pm 11.19$ & \\
\hline 85-93 & $114.06 \pm 24.37$ & & $41.73 \pm 10.82$ & \\
\hline \multicolumn{5}{|l|}{ Level of education } \\
\hline Illiterate & $117.51 \pm 17.68$ & \multirow{2}{*}{$>0.05$} & $43.41 \pm 8.25$ & \multirow{2}{*}{$>0.05$} \\
\hline Literate & $119.08 \pm 25.12$ & & $43.51 \pm 13.37$ & \\
\hline \multicolumn{5}{|l|}{ Marital status } \\
\hline Married & $124.66 \pm 13.15$ & \multirow{2}{*}{$<0.05$} & $43.40 \pm 9.75$ & \multirow{2}{*}{$>0.05$} \\
\hline Widow/ers divorced & $116.86 \pm 21.44$ & & $43.46 \pm 10.44$ & \\
\hline \multicolumn{5}{|l|}{ Monthly income (USD) } \\
\hline $40-345$ & $115.85 \pm 21.42$ & \multirow{2}{*}{$>0.05$} & $42.48 \pm 10.94$ & \multirow{2}{*}{$>0.05$} \\
\hline $345-692$ & $122.00 \pm 18.42$ & & $45.19 \pm 8.89$ & \\
\hline \multicolumn{5}{|l|}{ Chronic diseases } \\
\hline Present & $118.37 \pm 23.83$ & \multirow{2}{*}{$>0.05$} & $42.88 \pm 11.40$ & \multirow{2}{*}{$>0.05$} \\
\hline Absent & $117.98 \pm 19.67$ & & $43.61 \pm 10.03$ & \\
\hline
\end{tabular}

TABLE 3: The distribution of health-promoting lifestyle behaviors profile scores according to level of quality of life scores $(n=136)$.

\begin{tabular}{|c|c|c|c|c|}
\hline \multicolumn{5}{|c|}{ WHOQOL-OLD scores } \\
\hline \multirow[t]{2}{*}{ HPLP subscale scores } & $\begin{array}{c}\text { Poor QoL } \\
\text { Scores below average } \\
(6.25-43.44 p)\end{array}$ & $\begin{array}{c}\text { Good QoL } \\
\text { Scores above average } \\
(43.45-72.92 p)\end{array}$ & \multicolumn{2}{|c|}{ Statistical evaluation } \\
\hline & $X \pm \mathrm{SD}$ & $X \pm \mathrm{SD}$ & $t$ & $P$ \\
\hline Self-actualization & $30.74 \pm 7.74$ & $36.22 \pm 6.31$ & 4.506 & $<0.001$ \\
\hline Health responsibility & $21.85 \pm 5.12$ & $24.36 \pm 4.47$ & 3.013 & 0.003 \\
\hline Exercise & $7.75 \pm 3.06$ & $8.91 \pm 3.35$ & 2.119 & 0.036 \\
\hline Nutrition & $16.14 \pm 2.40$ & $17.26 \pm 2.25$ & 2.795 & 0.006 \\
\hline Interpersonal support & $17.50 \pm 4.79$ & $19.75 \pm 4.20$ & 2.894 & 0.004 \\
\hline Stress management & $16.37 \pm 4.15$ & $18.41 \pm 3.16$ & 3.193 & 0.002 \\
\hline Total score & $110.34 \pm 21.84$ & $124.93 \pm 16.64$ & 4.333 & $<0.001$ \\
\hline
\end{tabular}

${ }^{*}$ The average scores of WHOQOL-OLD: $43.45 \pm 10.30$, range 6.25-72.92.

self-actualization, health responsibility, exercise, nutrition, interpersonal support, and stress management.

In the logistic regression analysis performed, the only determining factor upon quality of life level was found to be the self-actualization scale (Wald: 15.92, Exp (B) 1.119, 95\% CI: (1.059-1.183), $P<0.001)$.

\section{Discussion}

Life expectancy at birth has increased in modern times; this fact results in our living for a considerable number of years. Therefore, achieving a good quality of life interm of health has become a universal goal in almost every society. Included among the 21st century goals of the WHO is the adoption by 2015 of healthy lifestyles in general, with special attention to substantially increasing healthy behaviors regarding nutrition, physical activity, and sexuality [20]. The long-term results of health-promoting behavior, which is one of the most important factors in enhancing health, are increases in life span and quality of life. Health-promoting behaviors play a key role, especially in the geriatric population, in protecting against diseases and disabilities and in enhancing well being and improving functional capacity [21].

In general healthy lifestyle is vital in daily living for an individual in old age and there are many factors that affect health-promoting behaviors. These factors might include demographic variables, level of income and education, situational factors, and interpersonal interaction [22]. 


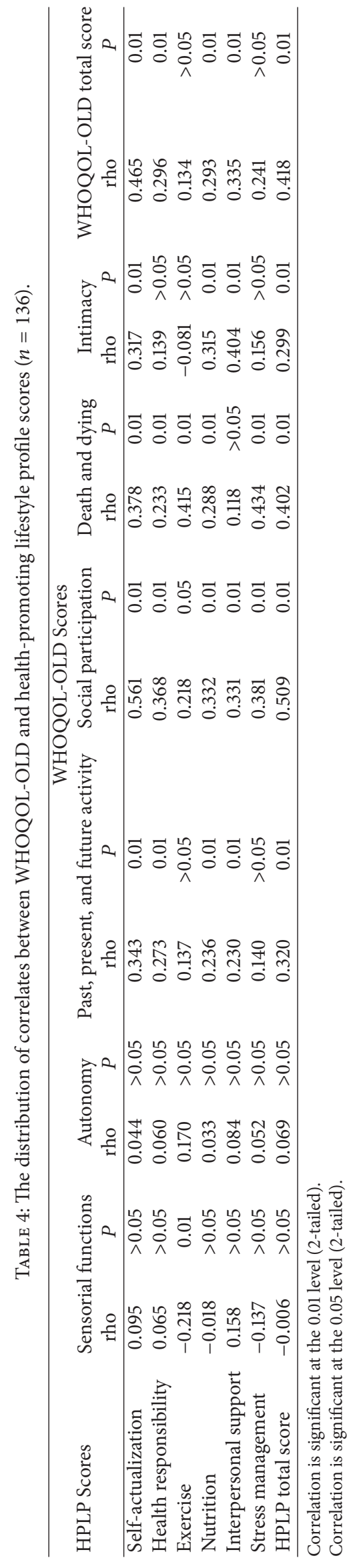


In this study except for gender and marital status all demographic variables have no significant association with health-promoting behaviors. Gender was not only related to the total HPLP scores but also significantly related to six HPLP subdomains. HPLP scores were significantly higher in males than females, which is consistent with the findings of previous studies [3, 23-25]. Accordingly overall HPLP score was higher in married subjects than widow/ers divorced. Kücükberber et al. [23] observed higher HPLP score in married subjects than single.

In our study there is no significant relation between level of education, monthly income, and overall HPLP score. However, many researchers [23-26] reported that as the aducational and economic status increased health-promoting behaviors and HPLP scores also increased.

In our study the mean overall HPLP score of the study group was $118.06 \pm 20.54$ (range 55-156), which determines a good level in health-promoting behaviors. This result is also in agreement with the opinion "as one gets older, the level of health-promoting behaviors increases" $[22,24]$. This can be explained by the life experience and health consciousness one gains in the aging process. It has been reported that healthpromoting behavior increases with age and is affected in a positive way [27]. One of the advantages of living a long life, is the wisdom one gains through achieving many goals and fulfilling one's desires while one is young; this impacts positively personality and social life. These experiences contribute to life satisfaction and have a positive effect. The increase in the mean HPLP scores of the elderly emphasizes the importance of being able to stay as healthy as possible and maintains a high quality of life, in spite of the losses they might have gone through due to aging, life experience, their interpretation of the things going on around them, and their own medical experiences.

The highest scores from the HPLP subscales in our study group were seen in the self-actualization subscale $(33.63 \pm$ $7.52)$, and the lowest were in the exercise subscale $(8.36 \pm$ 3.26). In Kim et al.s [3] study found that institutionalized older adults reported lower self-actualization; Walker et al. [28] showed that self-actualization is the highest subscale score. Self-actualization comprises the actualization of personal goals, realizing self-potential, self-satisfaction, personal success, and scientific discoveries [29]. In accordance with previous studies [27] our study findings showed that selfactualization gains more importance with advancing age, whereas the will to exercise decreases. Studies performed in different areas of our country report that the lowest scores are also established in the exercise subscale of the HPLP scale [30-32]. In their study, Kücükberber et al. [23] found that the physical activity subscale score of the HPLP scale was higher in the 20-48 and 49-60 age groups compared to the 61-80 age group. It is stated that physical activity is among the most effective factors in promoting health, and that it is helpful in protecting quality of life in late adulthood and in achieving a long healthy life [33].

On the other hand, insufficient physical activity levels in society are a serious public health problem with severe consequences [34]. Regular physical activity with the purpose of promoting health and preventing diseases is recommended for the whole population [35]. As exercise capacity increases in an individual, the negative effect of sensorial function loss upon quality of life decreases; on the other hand, as social participation increases, fear and anxiety regarding death and dying decrease. In our opinion, the low exercise level found in our study group is not a result of aging, but rather a reflection of the general tendency in our population. As a matter of fact, in many studies performed independent of age in our country, the exercise level was found to be low in general [3033].

In our study more than half of the elderly subjects had a point higher than mean QoL score $43.45(\mathrm{SD}=10.30$, range 6-73), indicating that they evaluate their QoL as moderate. QoL is a complex phenomenon, and many factors are thought to influence [36]. Demographic variables and health promotion behaviors were among in these factors. In this study, in contrast to previous studies results [25] all demographic variables (gender, age, education, marital status, and montly income) and chronic diseases were not found to be significantly related to QoL. However some studies have reported that as age increases, the quality of life level decreases [23]. They have also shown that as one grows older, life satisfaction and quality of life decrease not only due to functional insufficiency, but also due to chronic diseases [37].

In addition, as time goes by, familial and environmental losses occur, and adaptation problems that arise from these sociocultural and industrial changes, as well as changes in how they are viewed by other people and in their value meaning to other people, may affect quality of life in a negative way.

The overall WHOQOL-OLD and overall HPLP scores showed a moderate positive correlation. Individuals have a high point than mean of quality of life score and also had significantly higher overall and subscale scores in healthpromoting behaviors. On the other hand, favorable healthpromoting behaviors had a positive effect upon quality of life, and as the subscale scores of health-promoting behaviors increased, except for sensory functionality and autonomy, the subdomain scores for quality of life also increased. There was a positive correlation between the overall scores of both scales. This is an expected result, as both aspects interact with each other. In other words, positiveness in one results in positiveness in the other, and vice versa. Kocoglu and Akın [24] reported a positive correlation between healthpromoting behaviors and quality of life scores. Physical activity has been found to be related with increased quality of life, due to low mortality rates and to protection and control against chronic diseases [16]. In the study by Lee et al. [25] the quality of life score $(22.82 \pm 5.31)$ in elderly individuals that exercised for at least 30 minutes three days a week was significantly higher compared to those that did not exercise. In a study by Pasinlioglu and Gozum [30] conducted in elderly people, using the SF-36 life quality scale, a positive relationship was established between physical activity and the subdomain scores for quality of life.

It can be concluded that elderly individuals that had higher points than mean QoL score are more satisfied compared to those who had lower points, because they have goals in life, they can assume their own health responsibilities, and 
they exercise, choose appropriate nutrition and meal times, communicate and sustain communication with immediate family and friends, and can diagnose sources of stress and manage them appropriately and thus increase their quality of life even more. In other words, both situations have a causal connection. The fact that the number of elderly individuals has increased in the population results, on the one hand, in their being able to share their experiences and wisdom as a positive social aspect; on the other hand, it necessitates the setting up of health and government policies to deal with possible problems such as loss of capability, loss of identity, or even social degradation. In addition there is a further need to organize a ministry and institutes to help the geriatric population and to create social awareness about the topic.

\section{Limitations}

Notable limitations of this study: in the literature, the lack of research on institutionalized older adults precludes a full comparison of these results with those previous studies. Since this was a descriptive study for a group of nursing home residing in an urban community in the middle anatolian of Turkey, the findings cannot be generalized to the Turkish elderly population in Turkey.

\section{Conflict of Interests}

The authors declare that there is no conflict of interests regarding the publication of this paper.

\section{References}

[1] Turkey Ministry of Health, Statistical Reports for Health, Goverment Printing Office, Ankara, Turkey, 2011.

[2] J. Sims, N. M. Kerse, L. Naccarella, and H. Long, "Health promotion and older people: the role of the general practitioner in Australia in promoting healthy ageing," Australian and New Zealand Journal of Public Health, vol. 24, no. 4, pp. 356-359, 2000.

[3] S. Y. Kim, E. Y. Jeon, S. R. Sok, and K. B. Kim, "Comparison of health-promoting behaviors of noninstitutionalized and institutionalized older adults in Korea," Journal of Nursing Scholarship, vol. 38, no. 1, pp. 31-35, 2006.

[4] B. Steen, "The importance of diagnostic procedures to ensure quality of health care in geriatric medicine. Examples from recent studies," Quality Assurance in Health Care, vol. 2, no. 3-4, pp. 387-392, 1990.

[5] E. L. Idler and S. Kasl, "Health perceptions and survival: do global evaluations of health status really predict mortality?" Journals of Gerontology, vol. 46, no. 2, pp. S55-S65, 1991.

[6] A. Haveman-Nies, L. C. P. G. M. de Groot, and W. A. van Staveren, "Dietary quality, lifestyle factors and healthy ageing in Europe: the SENECA study," Age and Ageing, vol. 32, no. 4, pp. 427-434, 2003.

[7] U. Onat, Yaşlanma ve Sosyal Hizmet. Yașlılık Gerçeği, Hacettepe Üniversitesi Hastaneleri Basımevi, Ankara, Turkey, 2004.

[8] B. Durgun and Y. Tümerdem, "Urbanization and services for the elderly," Turk Geriatri Dergisi, vol. 2, no. 3, pp. 115-120, 1999.

[9] S. Eser, G. Saatli, E. Eser, H. Baydur, and C. Fidaner, "The reliability and validity of the Turkish version of the world health organization quality of life instrument-older adults module (WHOQOL-Old)," Turkish Journal of Psychiatry, vol. 21, no. 1, pp. 37-48, 2010.

[10] H. Kudo, Y. Izumo, H. Kodamo et al., "Life satisfaction in older people," Geriatrics and Gerontology International, vol. 7, no. 1, pp. 15-20, 2007.

[11] Yaşam Kalitesi Rehberi, Hacettepe Üniversitesi, GEBAM, Ankara, Turkey, 2003.

[12] M. G. Lima, M. B. D. A. Barros, C. L. G. César, M. Goldbaum, L. Carandina, and M. C. G. P. Alves, "Health-related behavior and quality of life among the elderly: a population-based study," Revista de Saude Publica, vol. 45, no. 3, pp. 485-493, 2011.

[13] L. S. Acree, J. Longfors, A. S. Fjeldstad et al., "Physical activity is related to quality of life in older adults," Health and Quality of Life Outcomes, vol. 4, article 37, 2006.

[14] R. G. Laforge, J. S. Rossi, J. O. Prochaska, W. F. Velicer, D. A. Levesque, and C. A. Mchorner, "Stage of regular exercise and health-related quality of life," Preventive Medicine, vol. 28, no. 4, pp. 349-360, 1999.

[15] A. Drewnowski and W. J. Evans, "Nutrition, physical activity, and quality of life in older adults: summary," Journals of Gerontology A, vol. 56, no. 2, pp. 89-94, 2001.

[16] D. W. Molloy, E. Alemayehu, and R. Roberts, "Reliability of a standardized mini-mental state examination compared with the traditional mini-mental state examination," The American Journal of Psychiatry, vol. 148, no. 1, pp. 102-105, 1991.

[17] C. Gungen, T. Ertan, E. Eker, R. Yasar, and F. Engin, "Reliability and validity of the standardized mini mental state examination in the diagnosis of mild dementia in Turkish population," Turkish Journal of Psychiatry, vol. 13, no. 14, pp. 273-281, 2002.

[18] N. Esin, "Sağlıklı yaşam biçimi davranışları ölçeğinin Türkçeye uyarlanması," Hemşirelik Bülteni, vol. 12, no. 15, pp. 87-95, 1999.

[19] M. Bullinger, M. J. Power, N. K. Aaronson, D. F. Cella, and R. T. Anderson, "Creating and evaluating cross-cultural instruments," in Quality of Life and Pharmaco Economics in Clinical Trials, B. Spilker, Ed., Lippincott-Raven, Hagerstown, Md, USA, 1996.

[20] F. S. Antezana, C. M. Chollat-Traquet, and D. Yach, "Health for all in the 21st century," World Health Statistics Quarterly, vol. 51, no. 1, pp. 3-6, 1998.

[21] World Health Organization, Global Health Risks: Mortality and Burden of Disease Attributable to Selected Major Risks, World Health Organization, Geneva, Switzerland, 2009.

[22] F. Maurer and C. Smith, Community Health Nursing Theory and Practice, WB Saunders, Philadelphia, Pa, USA, 2000.

[23] N. Kücükberber, K. Ozdilli, and H. Yorulmaz, "Evaluation of factors affecting healthy life style behaviors and quality of life in patients with heart disease," The Anatolian Journal of Cardiology, vol. 11, pp. 619-626, 2011.

[24] D. Kocoglu and B. Akın, "The relationship of socioeconomic inequalities to healthy lifestyle behaviors and quality of life," Dokuz Eylül Üniversitesi Hemşirelik Yüksekokulu Elektronik Dergisi, vol. 2, no. 4, pp. 145-154, 2009.

[25] T. W. Lee, I. S. Ko, and K. J. Lee, "Health promotion behaviors and quality of life among community-dwelling elderly in Korea: a cross-sectional survey," International Journal of Nursing Studies, vol. 43, no. 3, pp. 293-300, 2006.

[26] K. Y. Sohng, S. Sohng, and H. A. Yeom, "Health-promoting behaviors of elderly Korean immigrants in the United States," Public Health Nursing, vol. 19, no. 4, pp. 294-300, 2002. 
[27] G. Guler, N. Guler, S. Kocatas, F. Yıldırım, and N. Akgul, "Behaviors of healthy life style of academic personnel who work at a university," Cumhuriyet Hemşirelik Dergisi, vol. 12, no. 3, pp. 1826, 2008.

[28] S. N. Walker, K. Volkan, K. R. Sechrist, and N. J. Pender, "Health-promoting life styles of older adults: comparisons with young and middle-aged adults, correlates and patterns," Advances in Nursing Science, vol. 11, no. 1, pp. 76-90, 1988.

[29] S. Unsar, K. M. Akgun, S. Kurt, and O. Erol, "Self-actualization levels of nurses and affecting factors," Dokuz Eylül Üniversitesi Hemşirelik Yüksekokulu Elektronik Dergisi, vol. 4, no. 1, pp. 2-6, 2011.

[30] T. Pasinlioglu and S. Gozum, "Health behaviors of health staff working in the primary health services," Cumhuriyet Üniversitesi Hemşirelik Yüksekokulu Dergisi, vol. 2, no. 2, pp. 60-68, 1998.

[31] M. Yalcınkaya, F. G. Ozer, and A. Y. Karamanoglu, "Evaluation of healthy lifestyle behaviors in health care workers," TAF Preventive Medicine Bulletin, vol. 6, no. 6, pp. 409-420, 2007.

[32] S. Ozkan and E. Y1lmaz, "The health-promoting lifestyles of nurses working at hospital," Fırat Sağlik Hizmetleri Dergisi, vol. 3, no. 7, pp. 90-105, 2008.

[33] M. S. Kaplan, J. T. Newsom, B. H. McFarland, and L. Lu, "Demographic and psychosocial correlates of physical activity in late life," The American Journal of Preventive Medicine, vol. 21, no. 4, pp. 306-312, 2001.

[34] N. A. Garrett, M. Brasure, K. H. Schmitz, M. M. Schultz, and M. R. Huber, "Physical inactivity: direct cost to a health plan," The American Journal of Preventive Medicine, vol. 27, no. 4, pp. 304-309, 2004.

[35] L. B. Robbins, N. J. Pender, V. S. Conn et al., "Physical activity research in nursing," Journal of Nursing Scholarship, vol. 33, no. 4, pp. 315-321, 2001.

[36] D. Raphael, I. Brown, R. Renwick, M. Cava, N. Weir, and K. Heathcote, "The quality of life of seniors living in the community: a conceptualization with implications for public health practice," Canadian Journal of Public Health, vol. 86, no. 4, pp. 228-233, 1995.

[37] B. A. J. Walters, R. D. Hays, K. L. Spritzer, M. Fridman, and W. B. Carter, "Health-related quality of life, depressive symptoms, anemia, and malnutrition at hemodialysis initiation," The American Journal of Kidney Diseases, vol. 40, no. 6, pp. 1185-1194, 2002. 


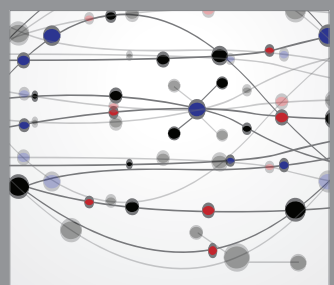

The Scientific World Journal
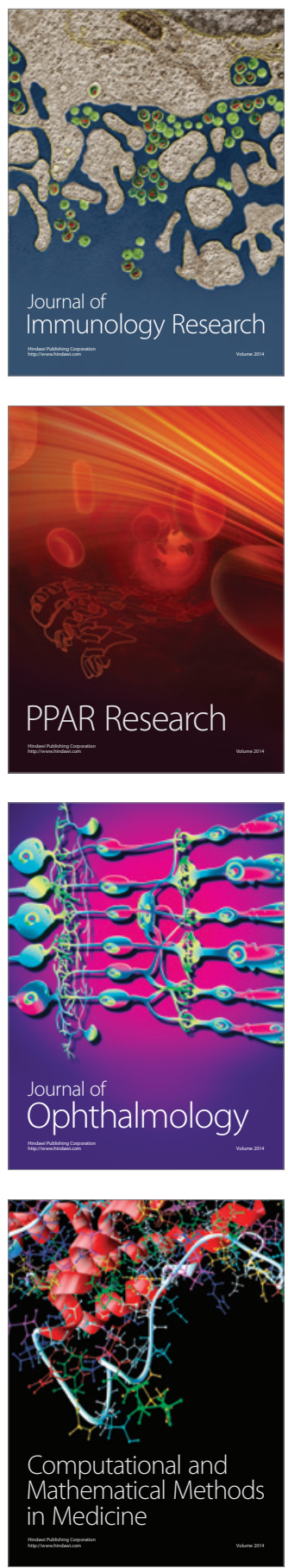

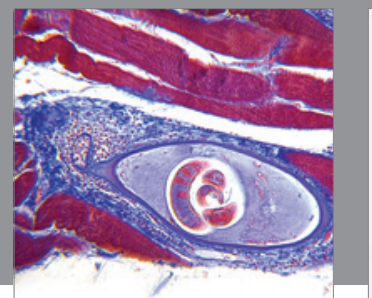

Gastroenterology

Research and Practice
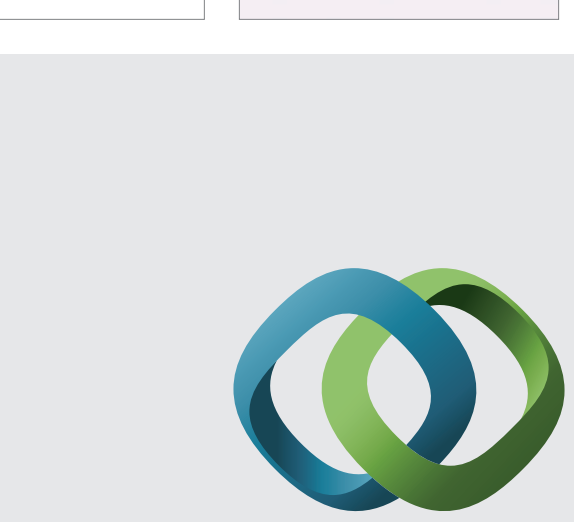

\section{Hindawi}

Submit your manuscripts at

http://www.hindawi.com
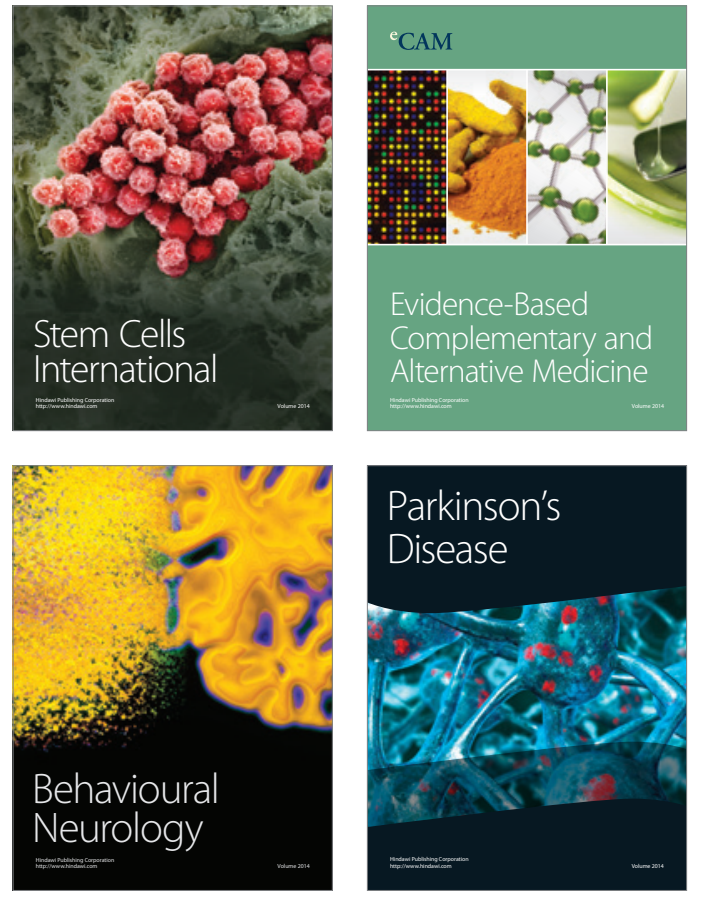
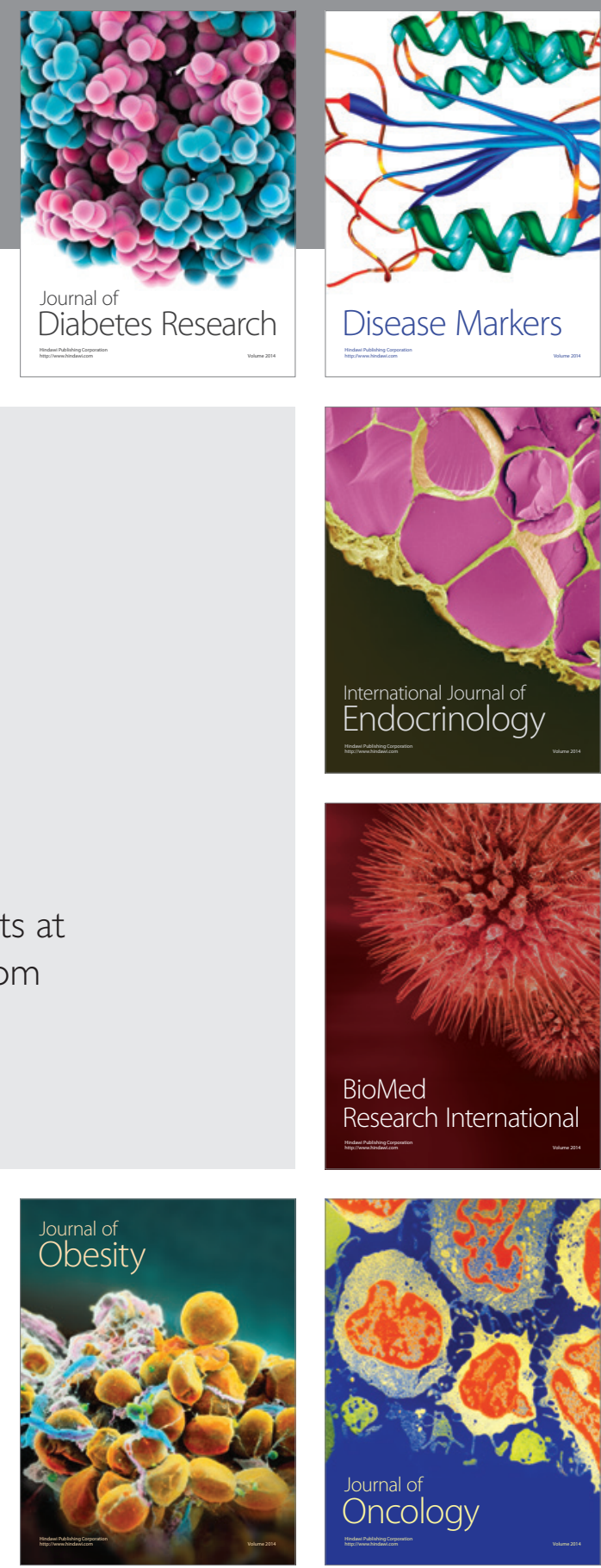

Disease Markers
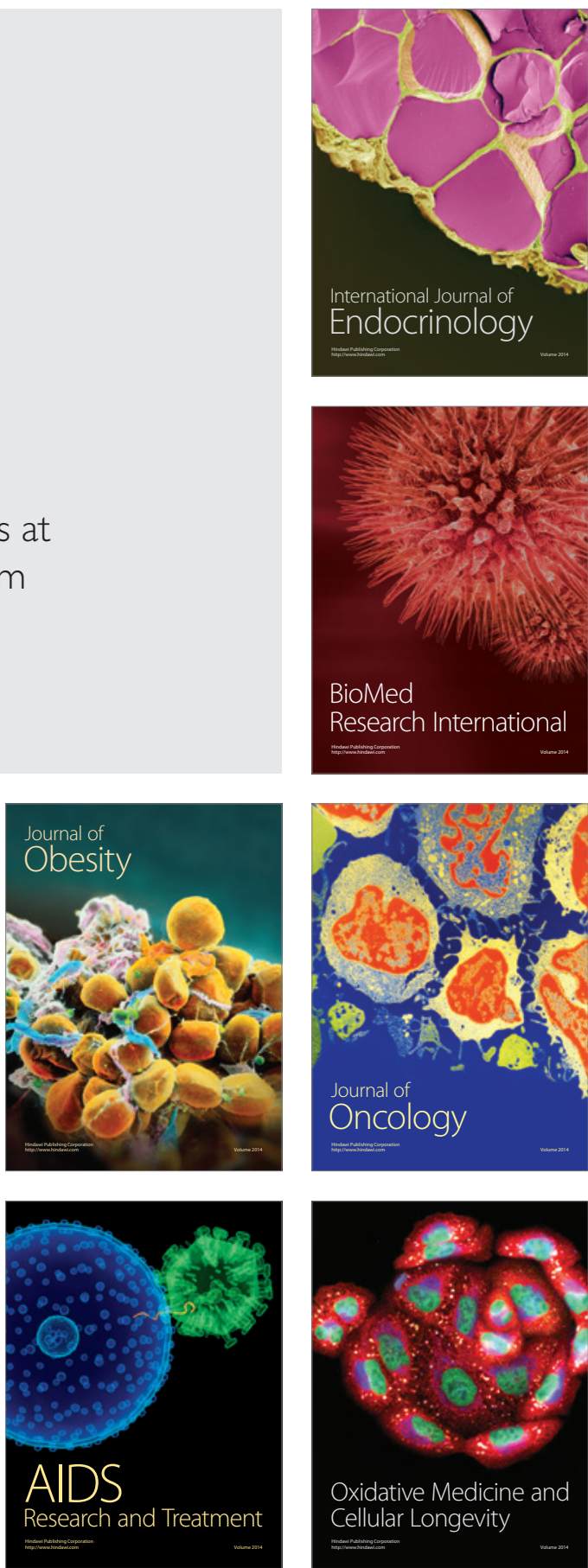